\title{
Six months of daily treatment with vardenafil improves parameters of endothelial inflammation and of hypogonadism in male patients with type 2 diabetes and erectile dysfunction: a randomized, double-blind, prospective trial
}

\author{
Daniele Santi ${ }^{1,2}$, Antonio R M Granata2 , Alessandro Guidi ${ }^{2}$, Elisa Pignatti ${ }^{1,3}$, \\ Tommaso Trenti ${ }^{4}$, Laura Roli ${ }^{4}$, Roberto Bozic ${ }^{5}$, Stefano Zaza ${ }^{6}$, Chiara Pacchioni ${ }^{7}$, \\ Stefania Romano7, Jerzy Roch Nofer ${ }^{8}$, Vincenzo Rochira ${ }^{1,2}$, Cesare Carani ${ }^{1}$ \\ and Manuela Simoni ${ }^{1,2,3}$

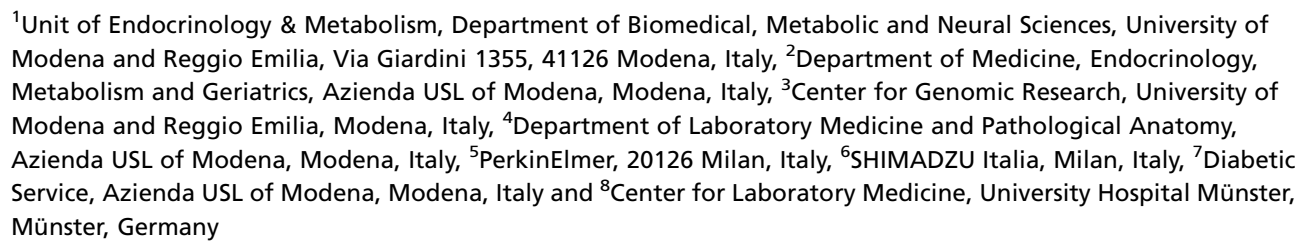

\author{
Correspondence \\ should be addressed \\ to $D$ Santi \\ Email \\ santi.daniele@gmail.com
}

\begin{abstract}
Objective: Type 2 diabetes mellitus (T2DM) is associated with endothelial dysfunction, characterized by a reduction of nitric oxide (NO)-mediated relaxation. Phosphodiesterase type 5 inhibitors (PDE5i) improve NO levels. The aim of the study was to investigate whether long-term, chronic treatment with the PDE5i vardenafil improves systemic endothelial function in diabetic men.

Design: A prospective, investigator-initiated, randomized, placebo-controlled, double-blind, clinical trial was conducted. Methods: In total, 54 male patients affected by T2DM, diagnosed within the last 5 years, and erectile dysfunction were enrolled, regardless of testosterone levels. In all, 26 and 28 patients were assigned to verum and placebo groups respectively. The study consisted of an enrollment phase, a treatment phase (24 weeks) (vardenafil/placebo $10 \mathrm{mg}$ twice in a day) and a follow-up phase (24 weeks). Parameters evaluated were as follows: International Index of Erectile Function 15 (IIEF-15), flow-mediated dilation (FMD), serum interleukin 6 (IL6), endothelin 1 (ET-1), gonadotropins and testosterone (measured by liquid chromatography/tandem mass spectrometry).

Results: IIEF-15 erectile function improved during the treatment $(P<0.001)$. At the end of the treatment both FMD $(P=0.040)$ and IL6 ( $P=0.019)$ significantly improved. FMD correlated with serum testosterone levels $\left(R^{2}=0.299 ; P<0.001\right)$. Testosterone increased significantly under vardenafil treatment and returned in the eugonadal range only in hypogonadal men $(n=13)$, without changes in gonadotropins. Chronic vardenafil treatment did not result in relevant side effects.

Conclusion: This is the first double-blind, placebo-controlled clinical trial designed to evaluate the effects of chronic treatment of vardenafil on endothelial health-related parameters and sexual hormones in patients affected by a chronic
\end{abstract} Printed in Great Britain
Published by Bioscientifica Ltd 
disease. Chronically administered vardenafil is effective and improves endothelial parameters in T2DM patient. Moreover, chronic vardenafil therapy improves hypogonadism in diabetic, hypogonadal men.

\section{Introduction}

Type 2 diabetes mellitus (T2DM) is a common chronic disease characterized by systemic inflammation causing progressive damage to the whole organism (1). Hyperglycaemia, insulin resistance and free fatty acids production are associated with endothelial dysfunction, representing the major role in DM comorbidity development $(1,2)$. Endothelial dysfunction advances through progressive stages: i) reduction in the availability of vasodilator molecules such as nitric oxide (NO); ii) increase of vasoconstrictor markers such as endothelial adhesionrelated molecules; and iii) increase of pro-inflammatory mediators such as interleukins (IL) and cytokines (3). NO is crucial for endothelial health, and conversely, reduction of NO availability is the first step in endothelial dysfunction. Physiologically, NO has a vasodilator effect through activation of guanylyl cyclase in vascular smooth muscle cells, where cyclic guanosine monophosphate (cGMP) is produced $(4,5)$. In experimental models of endothelial dysfunction due to T1 and T2DM, a reduction of NO availability has constantly been demonstrated (3). This is generally accompanied by an increase of proinflammatory mediators. In men, endothelial dysfunction is associated to erectile dysfunction.

Phosphodiesterase type 5 inhibitors (PDE5i) are indicated for the treatment of erectile dysfunction $(6,7)$. PDE is a family of enzymes modulating the intra-cellular concentration of second messengers, such as cAMP and cGMP, by controlling their rates of degradation (8). PDE5i facilitates penile erection, increasing the NO-dependent cGMP production in cavernous vascular smooth muscle cells $(6,7)$. In addition, PDE5i has cardiovascular effects, improving cardiac output with beneficial outcome on chronic congestive heart failure (9) and inducing remodeling of cardiac muscle cells and inhibiting platelet aggregation (10). Pre-clinical evidences show favorable PDE5i effects against inflammation $(11,12)$.

Recently, we performed a meta-analysis of six randomized clinical trials, which used chronic PDE5i in diabetic men, finding an overall beneficial effect on some endothelial health-related parameters, such as flowmediated dilation (FMD) and IL6 serum levels (13).
The aim of this study was to prospectively investigate the effect on endothelial function of 6-month daily treatment with oral vardenafil $20 \mathrm{mg}$ in patients with T2DM and erectile dysfunction, compared to placebo. Primary end points were endothelial health-related parameters including hemodynamic and serum biomarkers. The secondary end point was the evaluation of gonadal status, evaluating serum total testosterone levels by mass-spectrometry.

\section{Subjects and methods}

This is a longitudinal, prospective, randomized, placebocontrolled, double-blind, investigator-started, clinical trial. We enrolled patients with diagnosis of T2DM according to the guidelines of the European Association for the Study of Diabetes (14), made within 5 years before enrollment. All subjects were under appropriate treatment for T2DM and presented erectile dysfunction.

Patients were evaluated ten times during the study protocol (Figure S1, see section on supplementary data given at the end of this article). The study design included an enrollment phase lasting up to 4 weeks, a treatment phase of 24 weeks and a follow-up phase of 24 weeks. Inclusion criteria were: i) male gender; ii) T2DM diagnosed within 5 years; iii) BMI $<35 \mathrm{~kg} / \mathrm{m}^{2}$; iv) age between 40 and 65 years; and v) mild or severe erectile dysfunction. The latter condition was considered for a score lower than 26 at the erectile function domain of the International Index of Erectile Function 15 (IIEF-15) questionnaire. Patient exclusion criteria were: i) history of systemic diseases, when not strictly linked to diabetes; ii) history of psychiatric disorders; and iii) all contraindications to treatment with PDE5i (e.g. retinitis pigmentosa, nonarteritic anterior ischaemic optic neuropathy, history of coronary artery disease, recent myocardial infarction, unstable angina, systemic arterial hypotension, NO donors therapy, beta-blockers therapy, amiodarone, severe hepatic and renal failure).

The sample size was determined by power analysis assuming variations of the primary end point (serum 
endothelin 1 (ET-1)) of $0.7 \pm 0.7 \mathrm{pg} / \mathrm{ml}$ from baseline (15). Repeated measurement after baseline (ANCOVA), at $0.05 \alpha$ level, considering a two-sided test and 54 patients enrolled, was performed and the power was $94 \%$.

Patients were randomized through the permuted block method and assigned to the study or control groups, in which vardenafil (10 $\mathrm{mg}$ bid) and placebo were respectively administered. Vardenafil and placebo tablets were identical in shape, color and taste. The investigations performed at each of the ten study visits. A blood sample was taken at each visit after an overnight fast, in order to assay glucose, HbAlc, total cholesterol, HDL, LDL, triglycerides, glutamic oxaloacetic transaminase, glutamic pyruvic transaminase (GPT), alkaline phosphatase, creatinine, urea and fibrinogen. Urine sample was taken for physical and chemical examination. Two blood samples were left at room temperature for $30 \mathrm{~min}$ and then centrifuged at 3600 r.p.m. for $15 \mathrm{~min}$. Plasma and blood clots were removed and transferred into plain polypropylene tubes. Samples were taken and stored at $-20{ }^{\circ} \mathrm{C}$. At the end of the study, samples were used to assay IL6, ET-1, high-sensitivity C-reactive protein (hs-CRP), inter-cellular chemotactic protein 1 (ICAM-1), vascular cell adhesion molecule 1 (VCAM-1), luteinizing hormone (LH), follicle-stimulating hormone (FSH) and testosterone. During the first visit, patients underwent complete clinical workup including blood pressure, cardiac frequency, body weight, height and andrological examination. Furthermore, sexological information was obtained through the self-filled questionnaire IIEF-15 (16). At each of the ten visits, blood and urine collection, physical and andrological examination, and questionnaire administration were repeated. FMD was evaluated at the beginning of the study and at the end of both treatment (visit 8) and follow-up phases (visit 10).

\section{Instrumental examination}

FMD is an ultrasonographic parameter of endothelialdependent dilation, measuring the change in brachial artery diameter after $60 \mathrm{~s}$ of reactive hyperemia, compared with baseline measurements after deflation of a cuff placed around the forearm and inflated to $50 \mathrm{mmHg}$ above systolic blood pressure for $5 \mathrm{~min}$ (17). FMD was expressed in percentage and a score above $7 \%$ was considered normal $(17,18)$.

\section{Laboratory analysis}

ICAM-1 and VCAM-1 were measured on serum samples, diluted 1:2, using multiplex bead-based multiplex assay for Luminex platform (R\&D Systems, Inc., kit code LXSAH, Minneapolis, MN, USA). IL6 was measured on plasma samples by the Human IL6 Quantikine ELISA kit (R\&D Systems Europe, Ltd. Abingdon OX14 3NB, UK). Hs-CRP and ET-1 were measured with the BN II System instrument (Siemens) through a specific automated nephelometric assay (CardioPhase hs-CRP, Dada Behring, Inc., Newark, DE, USA). LH and FSH were assayed by ELISA. Testosterone was analyzed by liquid chromatography mass spectrometry (LCMS) (Shimadzu Nexera UHPLC with Shimadzu LCMS-8050 triple quadrupole) with the kit PelkinElmer (Wallac OY, Turku, Finland), using serum samples obtained at each visit. Other routine assays were performed using commercially available kits.

\section{Ethical}

The local Ethics Committee of the University of Modena and Reggio Emilia, Italy, approved the study protocol. Patient informed consent was obtained and patients were appropriately insured. The study was registered according to European study registration rules (EudraCT: 2009014137-25) and on ClinicalTrials.gov (identification number NCT02219646).

\section{Statistical analysis}

Statistical analysis was performed through the 'intentionto-treat' method. Variables were evaluated for distribution through the Kolmogorov-Smirnov test. Comparison among different groups was performed by univariate ANOVA when the variables showed parametric distribution, whereas Mann-Whitney or Kruskal-Wallis tests were applied for non-parametric values. Post hoc tests were performed by Dunnett test. Parameters were compared through linear regression analysis and Spearman's correlation coefficient.

Statistical analysis was performed using the 'Statistical Package for the Social Sciences' Software for Macintosh (version 21.0; SPSS, Inc.). For all comparisons, $P$ values $<0.05$ were considered statistically significant.

\section{Results}

In total, 54 patients were eligible and enrolled in the study according to the inclusion criteria (Fig. 1). In total, 26 patients were randomized to receive vardenafil (study group) for 6 months and 28 to placebo (control group) (Fig. 1). Twelve patients dropped out: six from the study and six from the control group (Fig. 1). Eight 


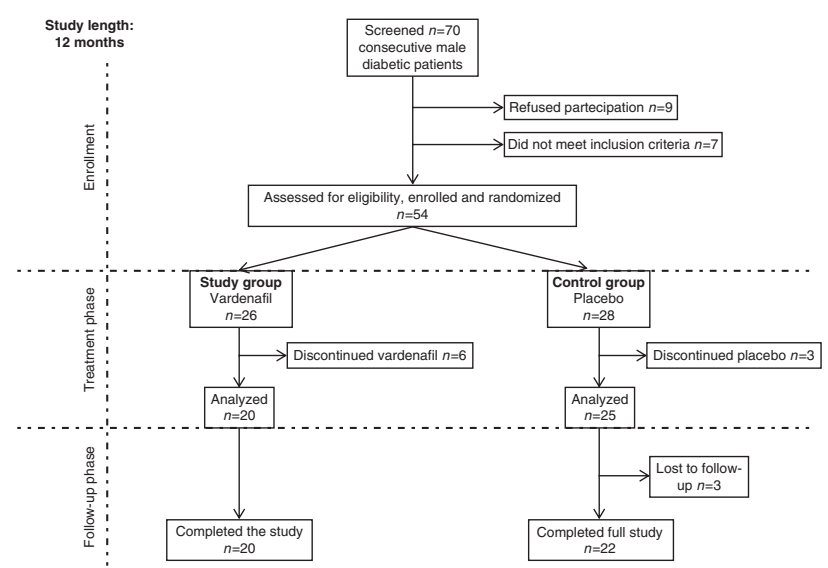

Figure 1

Study flow chart.

patients withdrew for adverse events not related to the drug and four patients for personal reasons (one patient moved to another city and three patients refused randomization).

ICAM-1, VCAM-1, hs-CRP and microalbuminuria were not normally distributed at Kolmogorov-Smirnov test.

Compliance to treatment was evaluated by assessing the number of tablets brought back by the patients at each visit after receiving a full blister at the previous visit. Compliance was not different between study and control groups (91 \pm 9 and $87 \pm 15 \%$ respectively) $(P=0.336)$.

Erectile function was evaluated by filling the IIEF-15. The score at the erectile function domain did not significantly differ at baseline between study and control groups $(P=0.614)$ (Table 1$)$, but it changed during the study, and at the end of the treatment phase (visit 8), it was significantly higher in the study than in the control group $(P<0.001)$ (Table 1$)$. This difference was lost at the end of the study (visit 10) $(P=0.853)$ (Table 1). In the study group, IIEF-15 erectile function domain significantly changed among the visits $(P<0.001)$, with a score higher at visit 8 than at baseline and at visit $10(P<0.001)$. In contrast, in the control group, the score at IIEF-15 erectile function domain showed lower values at the end of the study than at baseline and visit 8 at post hoc test $(P<0.001)$. Considering the known efficacy of vardenafil in the treatment of $\mathrm{ED}$, the improvement of erectile function domain at IIEF-15 confirmed compliance.

The mean age of patients was not different between study (55.8 \pm 5.0 years) and control group ( $55.0 \pm 5.0$ years) $(P=0.562)$. Similarly, there were no differences in months of T2DM diagnosis between study and control groups $(27.0 \pm 21.8$ and $29.0 \pm 18.2$ months respectively) $(P=0.743)$, confirming successful randomization. In total, 16 patients (57\%) in the control group and 18 patients (69\%) in the study group were treated with hypoglycemic drugs at baseline, without significant differences $(P=0.358)$. No significant vascular complications were present at baseline in both study and control groups.

Compliance was good in both groups and erectile function improved significantly in the study group (Table 1). No differences were seen between study and control groups considering hemoglobin and hematocrit.

Table 1 Endothelial health-related parameters in the 54 patients enrolled in the study. Values are expressed as mean \pm S.D. and Mann-Whitney test was performed for comparison.

\begin{tabular}{|c|c|c|c|}
\hline & Vardenafil & Placebo & $P$ value \\
\hline Number of patients & 26 & 28 & - \\
\hline \multicolumn{4}{|c|}{ IIEF-15 - erectile function domain } \\
\hline Baseline & $16.62 \pm 7.90$ & $17.68 \pm 7.51$ & 0.614 \\
\hline End of treatment & $26.00 \pm 4.59$ & $17.92 \pm 8.38$ & $<0.001$ \\
\hline End of follow-up & $14.38 \pm 5.73$ & $14.04 \pm 6.39$ & 0.853 \\
\hline$P$ value & $<0.001$ & $<0.001$ & \\
\hline \multicolumn{4}{|c|}{ Fibrinogen (mg/dl; NR: 150-450) } \\
\hline Baseline & $267.24 \pm 107.59$ & $312.71 \pm 51.45$ & 0.215 \\
\hline End of treatment & $272.50 \pm 85.77$ & $299.72 \pm 46.27$ & 0.187 \\
\hline End of follow-up & $270.35 \pm 67.28$ & $286.12 \pm 53.23$ & 0.385 \\
\hline$P$ value & 0.468 & 0.282 & \\
\hline \multicolumn{4}{|l|}{ FMD $(\% ;$ NR: $>7)$} \\
\hline Baseline & $6.83 \pm 3.89$ & $7.87 \pm 5.09$ & 0.308 \\
\hline End of treatment & $8.57 \pm 2.84$ & $6.41 \pm 2.77$ & 0.040 \\
\hline End of follow-up & $7.07 \pm 4.66$ & $6.22 \pm 3.49$ & 0.488 \\
\hline$P$ value & 0.295 & 0.194 & \\
\hline \multicolumn{4}{|c|}{ Hs-CRP (mg/dl; NR: <0.5) } \\
\hline Baseline & $0.22 \pm 0.35$ & $0.29 \pm 0.50$ & 0.510 \\
\hline End of treatment & $0.23 \pm 0.46$ & $0.19 \pm 0.19$ & 0.378 \\
\hline End of follow-up & $0.15 \pm 0.17$ & $0.21 \pm 0.18$ & 0.237 \\
\hline$P$ value & 0.890 & 0.926 & \\
\hline \multicolumn{4}{|l|}{ IL6 (pg/ml) } \\
\hline Baseline & $4.24 \pm 1.81$ & $4.01 \pm 1.29$ & 0.144 \\
\hline End of treatment & $2.67 \pm 0.99$ & $3.79 \pm 1.81$ & 0.017 \\
\hline End of follow-up & $2.69 \pm 0.90$ & $2.95 \pm 1.11$ & 0.871 \\
\hline$P$ value & $<0.001$ & $0 . \overline{181}$ & \\
\hline \multicolumn{4}{|c|}{ ET-1 (pg/ml; NR: 0.47-2.00) } \\
\hline Baseline & $1.43 \pm 0.37$ & $1.41 \pm 0.38$ & 0.819 \\
\hline End of treatment & $1.34 \pm 0.38$ & $1.42 \pm 0.40$ & 0.457 \\
\hline End of follow-up & $1.25 \pm 0.35$ & $1.37 \pm 0.45$ & 0.350 \\
\hline$P$ value & $0 . \overline{727}$ & 0.962 & \\
\hline \multicolumn{4}{|l|}{ ICAM-1 (ng/ml) } \\
\hline Baseline & $9.93 \pm 1.87$ & $1.30 \pm 2.21$ & 0.410 \\
\hline End of treatment & $7.12 \pm 1.77$ & $1.32 \pm 2.01$ & 0.664 \\
\hline End of follow-up & $7.42 \pm 1.82$ & $1.24 \pm 2.01$ & 0.689 \\
\hline$P$ value & $0 . \overline{514}$ & 0.825 & \\
\hline \multicolumn{4}{|l|}{ VCAM-1 (ng/ml) } \\
\hline Baseline & $8.0 \pm 3.2$ & $7.8 \pm 2.9$ & 0.887 \\
\hline End of treatment & $7.54 \pm 3.2$ & $7.09 \pm 2.64$ & 0.837 \\
\hline End of follow-up & $7.96 \pm 4.49$ & $7.07 \pm 2.34$ & 0.999 \\
\hline$P$ value & $0 . \overline{934}$ & $0 . \overline{374}$ & \\
\hline
\end{tabular}

NR, normal range. 


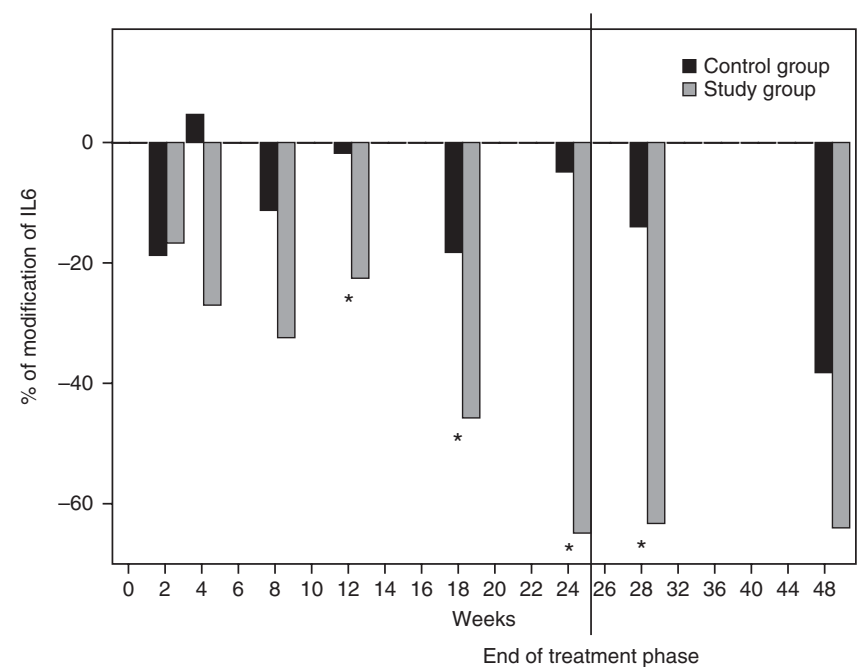

Figure 2

Comparison of FMD across visits in the study and control group. *Significant differences between study and control groups; $P=0.040$.

\section{Glycemic control}

Mean glucose serum levels were slightly above the normal range both in the study $(142 \pm 47 \mathrm{mg} / \mathrm{dl})$ and control groups $(136 \pm 35 \mathrm{mg} / \mathrm{dl})$ at baseline, without significant differences between the groups $(P=0.606)$ and across the visits. Similarly, no differences were seen in HbAlc and microalbuminuria. Concerning anti-diabetic treatment, 20 patients $(37 \%)$ were treated only with lifestyle modifications, 26 (48\%) with oral hypoglycemic drugs and eight (15\%) with oral drugs and insulin. No modification of anti-diabetic treatment was recorded during the study.

\section{Safety}

This is the first study evaluating chronic treatment with vardenafil, $20 \mathrm{mg}$ daily (10 $\mathrm{mg}$ bid) for 6 months (in diabetic men). Blood counts, liver and renal function were monitored throughout the study and remained in the normal range (data not shown). Therefore, chronic use of vardenafil is safe in diabetic patients. Adverse events - e.g. cough and bronchitis in six patients - were not related to treatment. Two serious adverse events occurred in the placebo group: one case of acute myocardial infarction and one case of syncope related to dyspnea and cough.

\section{Endothelial health-related parameters}

FMD scores were significantly higher in the study than in control group at visit $8(P=0.040)$, whereas no differences were seen at baseline and at visit $10(P=0.308$ and $P=0.488$ respectively) (Table 1 ) (Fig. 2). This confirms and extends previous reports on beneficial effects of PDE5i on hemodynamic parameters. FMD was inversely related only to red blood cell distribution width (RDW) at visit 8 only in the study group $\left(R^{2}=0.028 ; P=0.032\right)$.

IL6 was not different between study and control groups at baseline $(P=0.144)$ (Table 1$)$. No differences were observed from visits 2 to 5, whereas IL6 was significantly lower in the study than in the control group at visits 6,7 and $8(P=0.049, P=0.040$ and $P=0.017$ respectively) (Table 1 and Table S3, see section on supplementary data given at the end of this article). In addition, in the study group, IL6 was significantly lower at visits 8,9 and 10 compared to baseline $(P=0.019, P=0.030$ and $P=0.018$ respectively) at post hoc test (Table $\mathrm{S} 3$, see section on supplementary data given at the end of this article and Fig. 3).

Concerning the other parameters of endothelial function, ET-1, hs-CRP, ICAM-1 and VCAM-1 changed

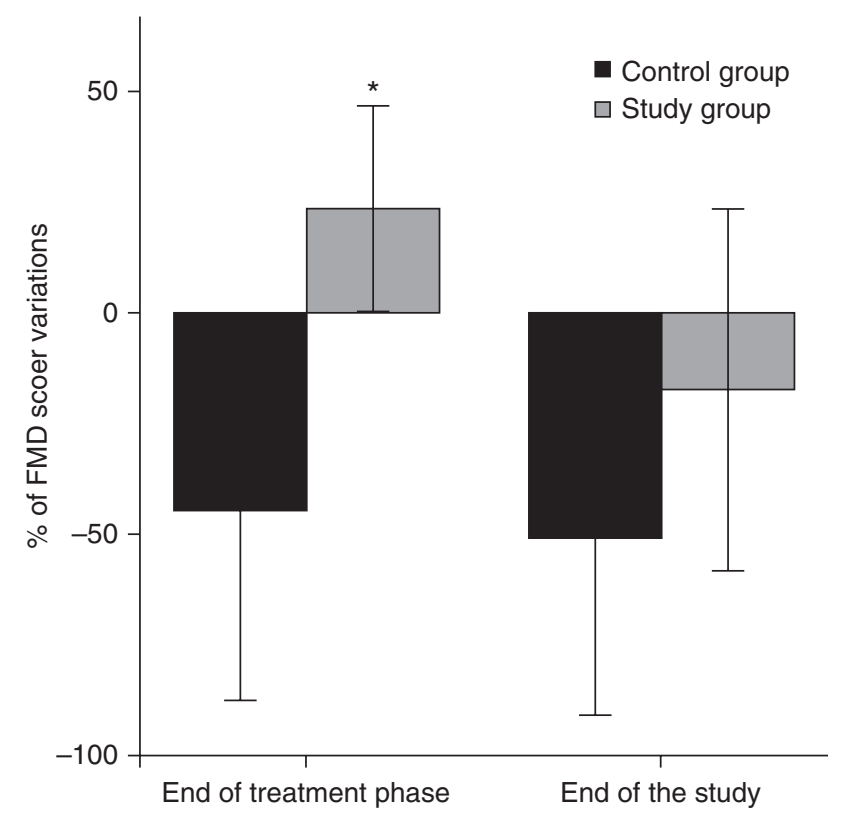

\section{Figure 3}

Comparison of IL6 serum levels across visits in the study and control groups. *Significant differences between study and control groups (values are reported in Table S3, see section on supplementary data given at the end of this article).

Error bars represented s.D. 
neither between groups nor across study visits (Table 1). However, there was a highly significant correlation between IL6 and hs-CRP both in the study and control groups ( $P<0.001$ and $P<0.001$ respectively) (Table $\mathrm{S} 2$, see section on supplementary data given at the end of this article). IL6 was positively correlated with ET-1, ICAM-1 and VCAM- 1 only in the study group $(P=0.015, P=0.002$ and $P=0.006$ respectively) (Table 2 ). These results suggest that chronic Vardenafil treatment impacts on endothelial, inflammation-related parameters, beneficially affecting endothelial function.

\section{Risk factors}

In total, 26 patients were smokers (48\%) and 28 nonsmokers (512\%), equally distributed between study (11 smoking patients, $42 \%$ ) and control groups (15 smoking patients, 58\%) ( $\chi^{2}$-test; $\left.P=0.873\right)$. As expected, smokers had significantly higher levels of IL6, hs-CRP and fibrinogen than non-smokers (Table S1, see section on supplementary data given at the end of this article). In the study group, these significant differences between smokers and non-smokers at baseline disappeared at visit 8, 9 and 10 . FMD scores did not change between smokers and nonsmokers. However, in smoking patients, FMD at the end of the treatment phase was significantly higher in the study than in the control group $(P=0.003)$. This improvement did not occur in non-smoking patients $(P=0.635)$ (Table $\mathrm{S} 1$, see section on supplementary data given at the end of this article).
Patients were subdivided into two subgroups depending on whether they were under pharmacological treatment for hypertension $(n=27,50 \%)$ or not $(n=27,50 \%)$. In either case, they were equally distributed between control $(n=14,51.85 \%)$ and study groups $(n=13,48.15 \%)$ $\left(\chi^{2}\right.$-test; $\left.P=0.070\right)$. The anti-hypertensive treatment did not change during the study in both groups. Hypertensive men had higher IL6, hs-CRP and fibrinogen than nonhypertensive men $(P<0.001)$ (Table $S 1$, see section on supplementary data given at the end of this article) with no differences among visits in response to treatment. These results suggest that the chronic vardenafil effect on endothelial function is different depending on the concomitance of classical risk factors for cardiovascular diseases.

\section{Gonadal status}

Total testosterone serum levels did not change between groups and across visits (Table 2). In total, 13 patients (24\%) were hypogonadal at baseline, according to the cutoff limit $(10.4 \mathrm{nmol} / \mathrm{l})$ proposed by the Endocrine Society (19), equally distributed between the study and the control groups ( $\chi^{2}$-test; $P=0.640$ ) (Table 2 ). In hypogonadal men, total testosterone serum levels significantly improved in the study compared to the control group and across visits (Table 2). In particular, total testosterone serum levels improved rapidly after 1 week of treatment, remaining in the normal range until the end of treatment phase (Table 2). After the end of therapy, testosterone

Table 2 Testosterone serum levels of the 54 patients enrolled in the study.

\begin{tabular}{|c|c|c|c|c|c|c|c|c|}
\hline & \multicolumn{3}{|c|}{ Non-hypogonadal patients } & \multicolumn{3}{|c|}{ Hypogonadal patients } & \multicolumn{2}{|c|}{$\begin{array}{l}\text { Non-hypogonadal vs } \\
\text { hypogonadal ( } P \text { value) }\end{array}$} \\
\hline & Vardenafil & Placebo & $P$ value & Vardenafil & Placebo & $P$ value & Vardenafil & Placebo \\
\hline $\begin{array}{l}\text { Number of patients } \\
\text { Testosterone (nmol/l) }\end{array}$ & 19 & 22 & & 7 & 6 & & & \\
\hline Visit $2^{a}$ & $16.04 \pm 3.57$ & $15.76 \pm 3.34$ & 0.795 & $7.95 \pm 1.59$ & $8.24 \pm 1.51$ & 0.628 & $<0.001$ & $<0.001$ \\
\hline Visit 3 & $14.04 \pm 7.15$ & $15.74+5.39$ & 0.414 & $14.40 \pm 5.99$ & $11.65 \pm 2.61$ & 0.999 & 0.919 & 0.103 \\
\hline Visit 4 & $14.71 \pm 6.22$ & $15.85 \pm 4.27$ & 0.519 & $14.21 \pm 8.44$ & $10.46 \pm 2.60$ & 0.537 & 0.881 & 0.014 \\
\hline Visit 5 & $12.95 \pm 5.29$ & $13.91 \pm 4.14$ & 0.559 & $13.90 \pm 8.80$ & $10.74 \pm 3.34$ & 0.699 & 0.763 & 0.020 \\
\hline Visit 6 & $13.31 \pm 4.43$ & $14.67 \pm 3.80$ & 0.349 & $11.26 \pm 5.47$ & $11.48 \pm 2.70$ & 0.792 & 0.387 & 0.094 \\
\hline Visit 7 & $14.09 \pm 5.73$ & $13.84 \pm 3.66$ & 0.887 & $8.86 \pm 2.45$ & $10.46 \pm 4.33$ & 0.143 & 0.070 & 0.099 \\
\hline Visit $8^{b}$ & $13.17 \pm 5.84$ & $14.40 \pm 5.24$ & 0.247 & $13.69 \pm 3.03$ & $6.93 \pm 3.34$ & 0.010 & 0.840 & 0.005 \\
\hline Visit 9 & $13.19 \pm 4.55$ & $15.02 \pm 4.41$ & 0.351 & $8.88 \pm 1.63$ & $10.91 \pm 8.28$ & 0.143 & 0.154 & 0.022 \\
\hline $\begin{array}{r}\text { Visit } 10^{c} \\
P \text { value }\end{array}$ & $\begin{array}{c}13.94 \pm 4.55 \\
0.836\end{array}$ & $\begin{array}{c}14.65 \pm 3.47 \\
0.751\end{array}$ & 0.612 & $\begin{array}{l}9.01 \pm 1.63 \\
0.036\end{array}$ & $\begin{array}{c}6.27 \pm 4.33 \\
0.081\end{array}$ & 0.548 & 0.020 & 0.001 \\
\hline
\end{tabular}


levels rapidly returned into the hypogonadal range (Table 2). This result suggests that vardenafil rapidly improves and maintains normal testosterone production in hypogonadal men. In hypogonadal patients, LH was not different between the study and the control groups at baseline $(5 \pm 5 \mathrm{mIU} / \mathrm{ml}$ vs $3 \pm 1 \mathrm{mIU} / \mathrm{ml} ; P=0.431)$, during the study until visit $8(6 \pm 7 \mathrm{mIU} / \mathrm{ml}$ vs $3 \pm 1 \mathrm{mIU} / \mathrm{ml}$; $P=0.748)$ and $10(6 \pm 7 \mathrm{mIU} / \mathrm{ml}$ vs $3 \pm 2 \mathrm{mIU} / \mathrm{ml}$; $P=0.134)$. Similarly, LH did not change across visits both in the study $(P=0.976)$ and control groups $(P=0.849)$. Given the high heterogeneity of the LH values, the role of LH on the beneficial effect of vardenafil on testosterone production remains unclear. No changes in testosterone serum levels occurred in non-hypogonadal men.

No correlations between endothelial health-related parameters and blood cell variables were found in hypogonadal and non-hypogonadal men. However, at the end of treatment phase, an inverse correlation between FMD and RDW $\left(R^{2}=0.028 ; P=0.032\right)$ was found in hypogonadal men treated with vardenafil. The correlation between FMD and RDW seen in the study group was maintained only in hypogonadal men. This result suggests beneficial effects of vardenafil on RDW in chronically treated, hypogonadal men returning to eugonadism.

\section{Discussion}

This is the first prospective, non-sponsored clinical trial in which vardenafil $20 \mathrm{mg}$ daily was used for long-term treatment (in diabetic men with erectile dysfunction). Chronic vardenafil was able to improve penile and systemic endothelial function in diabetic men, without any drug-related adverse events during the 6 months of treatment. Its efficacy was rapidly lost after withdrawal.

To the best of our knowledge, no other studies ever evaluated the effect of this specific PDE5i on endothelial function for such a long period. Chronic vardenafil results in decreased IL6 serum levels after 6 months of treatment, maintaining its beneficial effect during withdrawal. IL6 belongs to the family of pro-inflammatory cytokines, known mediators of inflammation, endothelial dysfunction and atherosclerosis (20). Recently, IL6 was proposed as a regulator of cell senescence (21) and marker of cardiovascular risk (22), being related to cardiovascular mortality (23). Here, we demonstrate that IL6 is positively related to hs-CRP and ET-1, although vardenafil did not influence these endothelial parameters. A meta-analysis of the available data in the literature suggested that chronic treatment with the PDE5i sildenafil decreases IL6 serum levels in diabetic men (13). However, daily administration of sildenafil was continued only for up to 12 weeks as the longest duration of therapy so far. In this longitudinal, prospective clinical trial, we demonstrate for the first time the beneficial effects of vardenafil on endothelial function extending the chronic use of a PDE5 inhibitor for a much longer duration of low-dose administration. We show that the reduction in endothelial inflammation was maintained after treatment withdrawal, suggesting a long-lasting, positive effect on chronic inflammation.

FMD is a well-known and reliable hemodynamic parameter of endothelial function. Data from the literature demonstrate an FMD improvement after chronic (13, $24,25,26,27)$ and acute sildenafil administration in diabetic men (28). By using vardenafil, here, we demonstrate that FMD improves during treatment. However, FMD did not correlate with endothelial serum biomarkers, suggesting that FMD and biomarkers evaluate two different aspects of the vasodilation and chronic inflammation. Accordingly, FMD improvement was lost after treatment withdrawal, while IL6 remained at significantly lower levels, demonstrating that hemodynamic parameter modifications can be explained only in part by endothelial biomarkers.

Chronic vardenafil administration significantly increased testosterone in hypogonadal, diabetic men, restoring eugonadism. This is the first in vivo demonstration, through a placebo-controlled, randomized, prospective design, of a beneficial effect of vardenafil on testosterone serum levels, measured using mass spectrometry. We show that PDE5i can improve testosterone production in hypogonadal men, although the mechanism remains unclear. Several observational trials suggested an improvement of total testosterone serum levels in men with erectile dysfunction after 3 months of various therapies $(29,30)$. These authors suggested that the improvement of testosterone levels was a consequence of improved sexual activity in men using impotence drugs $(29,30)$. In this way, testosterone deficiency was interpreted both as the cause and the effect of impotence (30). In the current study, a significant testosterone increase was already evident after 1 week of continuous vardenafil treatment, even if it was not matched by significant LH changes. Since the IIEF-15 score improved, although not significantly, also in the study group, these results suggest that vardenafil and, possibly, other PDE5i might increases testosterone serum levels independently from sexual activity (and LH), perhaps through a direct effect of the PDE5 inhibitor either on testicular vasodilation, or on Leydig cell function or both. The latter mechanism was 
suggested in animal models. Prolonged PDE5i in rats stimulates Leydig cell steroidogenesis, through a coordinate stimulatory effect of cAMP and cGMP (31). Both of these messengers act synergistically and converge on steroidogenic acute regulatory protein to enhance testosterone production $(31,32)$.

RDW was inversely related to FMD at the end of vardenafil administration. RDW is a quantitative measure of variability in the size of circulating erythrocytes, with higher values reflecting greater heterogeneity in cell sizes (33). Recently, high RDW values were demonstrated to be associated with increased mortality risk for cardiovascular diseases and considered a powerful predictor of cardiovascular mortality (33). We could speculate that chronic vardenafil treatment, by reducing endothelial dysfunction, may reduce mortality risk, as suggested by the RDW trend. However, the association between PDE5i administration and mortality risk needs further confirmation.

Several studies reported a correlation between ET-1 and adhesion molecules with endothelial function $(34,35)$. These parameters were proposed as markers of endothelial function (24). In contrast with previous results (24), we did not observe a decrease of these parameters. Furthermore, we found no differences in these serum variables when subgrouping the patients according to the presence/absence of possibly confounding factors, such as smoking habit or hypertension. This discrepancy is unlikely to be related to the different PDE5i used, while methodological differences in the assays used for these measurements in each study might play a role. It is well known that cytokines assays suffer of a wide number of assay-to-assay variation, leading to out-of-range values (36). Nevertheless, we demonstrated for the first time a strong correlation between IL6 serum levels ET-1, ICAM-1 and VCAM-1, not seen before (37), suggesting that all of these parameters reflect the inflammatory state affecting the endothelium.

Endothelial function is influenced by several variables including cigarette smoke. The improvement of FMD after vardenafil treatment in smokers suggests that vardenafil may be able to counteract the pro-inflammatory effects of smoking. Similar results were obtained for patients with hypertension, suggesting a similar mechanism between these two risk factors.

In conclusion, we found that chronic PDE5i improves endothelial parameters and, in hypogonadal men with T2DM, serum testosterone levels. This protective endothelial effect should not necessarily be limited to the male gender. Up to now there is limited experience about PDE5i use in women. However, endothelial dysfunction, typical of chronic diseases, is similar in both genders, and women benefit from these drugs in, e.g., Raynaud syndrome. Thus, we might reasonably expect beneficial endothelial effects in T2DM in women as well, but this needs to be tested experimentally. In addition, the effects of PDE5i should be further investigated in male hypogonadism. The opportunity of testosterone treatment in men with late-onset hypogonadism represents a highly controversial issue (19). These men often present several comorbidities, from hypotestosteronemia to endothelial dysfunction, diabetes and atherosclerosis. PDE5i may be useful in such men, in which we obtained an improvement of the indexes of chronic inflammation, of erectile function and of circulating testosterone using a single drug. Thus, the chronic use of PDE5i could become a new therapeutic option of chronic inflammation and endothelial dysfunction at large.

\section{Supplementary data}

This is linked to the online version of the paper at http://dx.doi.org/10.1530/ EJE-15-1100.

\section{Declaration of interest}

The authors declare that there is no conflict of interest that could be perceived as prejudicing the impartiality of the research reported.

\section{Funding}

This research did not receive any specific grant from any funding agency in the public, commercial or not-for-profit sector.

\begin{abstract}
Author contribution
A R M Granata, C Carani and M Simoni designed the study protocol. D Santi, A R M Granata, A Guidi, C Pacchioni, S Romano, V Rochira and C Carani provided the patients enrollment. D Santi and A Guidi followed patients during the study. Testosterone Trenti, L Roli and E Pignatti provided the laboratory analysis. R Bozic and S Zaza performed the testosterone measurements. D Santi, A R M Granata, J R Nofer, V Rochira and M Simoni finalized the manuscript.
\end{abstract}

\begin{abstract}
Acknowledgements
We thank Dr Francesca Linari, Dr Giorgia Spaggiari, Dr Erica Taliani and Mrs Graziella Martinelli for helping in patient management. The 'Associazione Scientifica in Endocrinologia, Andrologia e Metabolismo', Carpi, Italy, supported the study. Bayer HealthCare Italy prepared and provided drug and placebo kits. Thanks to Dr Diego Scannerini, Shimadzu Italy, for the management of steroid measurements. The skillful assistance in FMD measurements of Mrs Antonella Lattanzi, certified sonographer for the study of endothelial function, Unit of Cardiology of the Azienda
\end{abstract}


Ospedaliero-Universitaria Policlinico di Modena, is gratefully acknowledged. Daniele Santi, MD, is a PhD fellow of the Doctorate School in Clinical and Experimental Medicine of the University of Modena and Reggio Emilia, Italy, and obtained the Young Investigator Award at the European Congress of Endocrinology 2015 for this study.

\section{References}

1 American Diabetes Association. Diagnosis and classification of diabetes mellitus. Diabetes Care 201033 (Suppl 1) S62-69.

2 Kearney MT, Duncan ER, Kahn M \& Wheatcroft SB. Insulin resistance and endothelial cell dysfunction: studies in mammalian models. Experimental Physiology 200893 158-163. (doi:10.1113/expphysiol. 2007.039172)

3 Lubos E, Handy DE \& Loscalzo J. Role of oxidative stress and nitric oxide in atherothrombosis. Frontiers in Bioscience 200813 5323-5344. (doi:10.2741/3084)

4 Antonopoulos AS, Margaritis M, Coutinho P, Shirodaria C, Psarros C, Herdman L, Sanna F, De Silva R, Petrou M, Sayeed R et al. Adiponectin as a link between type 2 diabetes mellitus and vascular NADPH-oxidase activity in the human arterial wall: the regulatory role of perivascular adipose tissue. Diabetes 201564 2207-2219. (doi:10.2337/db14-1011)

5 La Vignera S, Condorelli R, Vicari E, D’Agata R \& Calogero AE. Endothelial antioxidant compound prolonged the endothelial antiapoptotic effects registered after tadalafil treatment in patients with arterial erectile dysfunction. Journal of Andrology 201233 170-175. (doi:10.2164/jandrol.111.013342)

6 Corbin JD. Mechanisms of action of PDE5 inhibition in erectile dysfunction. International Journal of Impotence Research 200416 (Suppl 1) S4-S7. (doi:10.1038/sj.ijir.3901205)

7 Rosen RC \& Kostis JB. Overview of phosphodiesterase 5 inhibition in erectile dysfunction. American Journal of Cardiology 200392 9M-18M. (doi:10.1016/S0002-9149(03)00824-5)

8 Bender AT \& Beavo JA. Cyclic nucleotide phosphodiesterases: molecular regulation to clinical use. Pharmacological Reviews 200658 488-520. (doi:10.1124/pr.58.3.5)

9 Kapur V, Chien CV, Fuess JE \& Schwarz ER. The relationship between erectile dysfunction and cardiovascular disease. Part II: the role of PDE-5 inhibition in sexual dysfunction and cardiovascular disease. Reviews in Cardiovascular Medicine 20089 187-195. (doi:10.2459/JCM. 0b013e32815aa7ef)

10 Dunkern TR \& Hatzelmann A. The effect of Sildenafil on human platelet secretory function is controlled by a complex interplay between phosphodiesterases 2, 3 and 5. Cellular Signalling 200517 331-339. (doi:10.1016/j.cellsig.2004.07.007)

11 Roumeguere T, Zouaoui Boudjeltia K, Babar S, Nuyens V, Rousseau A, Van Antwerpen P, Ducobu J, Wespes E \& Vanhaeverbeek M. Effects of phosphodiesterase inhibitors on the inflammatory response of endothelial cells stimulated by myeloperoxidase-modified low-density lipoprotein or tumor necrosis factor $\alpha$. European Urology 201057 522-528. (doi:10.1016/j.eururo.2009.01.030)

12 Vignozzi L, Gacci M, Cellai I, Santi R, Corona G, Morelli A, Rastrelli G, Comeglio P, Sebastanelli A, Maneschi E et al. Fat boosts, while androgen receptor activation counteracts, $\mathrm{BPH}$-associated prostate inflammation. Prostate 201373 789-800. (doi:10.1002/pros.22623)

13 Santi D, Giannetta E, Isidori AM, Vitale C, Aversa A \& Simoni M. Therapy of endocrine disease: effects of chronic use of phosphodiesterase inhibitors on endothelial markers in type 2 diabetes mellitus: a meta-analysis. European Journal of Endocrinology 2015172 R103-R114. (doi:10.1530/EJE-14-0700)

14 Alberti KG \& Zimmet PZ. Definition, diagnosis and classification of diabetes mellitus and its complications. Part 1: diagnosis and classification of diabetes mellitus provisional report of a WHO consultation. Diabetic Medicine 199815 539-553. (doi:10.1002/ (SICI) 1096-9136(199807)15:7 < 539::AID-DIA668 > 3.0.CO;2-S)

15 Rosano GM, Aversa A, Vitale C, Fabbri A, Fini M \& Spera G. Chronic treatment with tadalafil improves endothelial function in men with increased cardiovascular risk. European Urology 200547 214-220; discussion 220-212. (doi:10.1016/j.eururo.2004.10.002)

16 Rosen RC, Riley A, Wagner G, Osterloh IH, Kirkpatrick J \& Mishra A. The international index of erectile function (IIEF): a multidimensional scale for assessment of erectile dysfunction. Urology 199749 822-830. (doi:10.1016/S0090-4295(97)00238-0)

17 Corretti MC, Anderson TJ, Benjamin EJ, Celermajer D, Charbonneau F, Creager MA, Deanfield J, Drexler H, Gerhard-Herman M, Herrington D et al. Guidelines for the ultrasound assessment of endothelialdependent flow-mediated vasodilation of the brachial artery: a report of the International Brachial Artery Reactivity Task Force. Journal of the American College of Cardiology 200239 257-265. (doi:10.1016/S0735-1097(01)01746-6)

18 Heiss C, Lauer T, Dejam A, Kleinbongard P, Hamada S, Rassaf T, Matern S, Feelisch M \& Kelm M. Plasma nitroso compounds are decreased in patients with endothelial dysfunction. Journal of the American College of Cardiology 200647 573-579. (doi:10.1016/j.jacc. 2005.06.089)

19 Bhasin S, Cunningham GR, Hayes FJ, Matsumoto AM, Snyder PJ, Swerdloff RS \& Montori VM. Testosterone therapy in men with androgen deficiency syndromes: an Endocrine Society clinical practice guideline. Journal of Clinical Endocrinology and Metabolism 201095 2536-2559. (doi:10.1210/jc.2009-2354)

20 Kaur J. A comprehensive review on metabolic syndrome. Cardiology Research and Practice 20142014943162. (doi:10.1155/2014/943162)

21 Kojima H, Inoue T, Kunimoto H \& Nakajima K. IL-6-STAT3 signaling and premature senescence. JAK-STAT 20132 e25763. (doi:10.4161/jkst. 25763)

22 de Araujo Freitas IG, de Bruin PF, Bittencourt L, de Bruin VM \& Tufik S. What can blood biomarkers tell us about cardiovascular risk in obstructive sleep apnea? Sleep \& Breathing 201519 755-768. (doi:10.1007/s11325-015-1143-9)

23 Su D, Li Z, Li X, Chen Y, Zhang Y, Ding D, Deng X, Xia M, Qiu J \& Ling W. Association between serum interleukin- 6 concentration and mortality in patients with coronary artery disease. Mediators of Inflammation 20132013 726178. (doi:10.1155/2013/726178)

24 Aversa A, Vitale C, Volterrani M, Fabbri A, Spera G, Fini M \& Rosano GM. Chronic administration of Sildenafil improves markers of endothelial function in men with Type 2 diabetes. Diabetic Medicine 200825 37-44. (doi:10.1111/j.1464-5491.2007.02298.x)

25 Desouza C, Parulkar A, Lumpkin D, Akers D \& Fonseca VA. Acute and prolonged effects of sildenafil on brachial artery flow-mediated dilatation in type 2 diabetes. Diabetes Care 200225 1336-1339. (doi:10.2337/diacare.25.8.1336)

26 Deyoung L, Chung E, Kovac JR, Romano W \& Brock GB. Daily use of sildenafil improves endothelial function in men with type 2 diabetes. Journal of Andrology 201233 176-180. (doi:10.2164/jandrol.111. 013367)

27 Giannetta E, Isidori AM, Galea N, Carbone I, Mandosi E, Vizza CD, Naro F, Morano S, Fedele F \& Lenzi A. Chronic Inhibition of cGMP phosphodiesterase $5 \mathrm{~A}$ improves diabetic cardiomyopathy: a randomized, controlled clinical trial using magnetic resonance imaging with myocardial tagging. Circulation 2012125 2323-2333. (doi:10.1161/ CIRCULATIONAHA.111.063412)

28 Stirban A, Laude D, Elghozi JL, Sander D, Agelink MW, Hilz MJ \& Ziegler D. Acute effects of sildenafil on flow mediated dilatation and cardiovascular autonomic nerve function in type 2 diabetic patients. Diabetes/Metabolism Research and Reviews 200925 136-143. (doi:10.1002/dmrr.921)

29 Carosa E, Martini P, Brandetti F, Di Stasi SM, Lombardo F, Lenzi A \& Jannini EA. Type $\mathrm{V}$ phosphodiesterase inhibitor treatments for erectile 
dysfunction increase testosterone levels. Clinical Endocrinology 200461 382-386. (doi:10.1111/j.1365-2265.2004.02108.x)

30 Jannini EA, Screponi E, Carosa E, Pepe M, Lo Giudice F, Trimarchi F \& Benvenga S. Lack of sexual activity from erectile dysfunction is associated with a reversible reduction in serum testosterone. International Journal of Andrology 199922 385-392. (doi:10.1046/ j.1365-2605.1999.00196.x)

31 Andric SA, Janjic MM, Stojkov NJ \& Kostic TS. Sildenafil treatment in vivo stimulates leydig cell steroidogenesis via the cAMP/cGMP signaling pathway. American Journal of Physiology. Endocrinology and Metabolism 2010299 E544-E550. (doi:10.1152/ajpendo.00337.2010)

32 Saraiva KL, Silva AK, Wanderley MI, De Araujo AA, De Souza JR \& Peixoto CA. Chronic treatment with sildenafil stimulates Leydig cell and testosterone secretion. International Journal of Experimental Pathology 200990 454-462. (doi:10.1111/j.1365-2613.2009.00660.x)

33 Patel KV, Semba RD, Ferrucci L, Newman AB, Fried LP, Wallace RB, Bandinelli S, Phillips CS, Yu B, Connelly S et al. Red cell distribution width and mortality in older adults: a meta-analysis. Journals of
Gerontology Series A, Biological Sciences and Medical Sciences 201065 258-265. (doi:10.1093/gerona/glp163)

34 Wautier JL \& Wautier MP. Molecular basis of erythrocyte adhesion to endothelial cells in diseases. Clinical Hemorheology and Microcirculation 201353 11-21. (doi:10.3233/CH-2012-1572)

35 Wautier JL \& Wautier MP. Molecular basis of red blood cell adhesion to endothelium. Annales Pharmaceutiques Françaises 201169 3-6. (doi:10.1016/j.pharma.2010.10.003)

36 Breen EJ, Polaskova V \& Khan A. Bead-based multiplex immuno-assays for cytokines, chemokines, growth factors and other analytes: median fluorescence intensities versus their derived absolute concentration values for statistical analysis. Cytokine 201571 188-198. (doi:10.1016/j. cyto.2014.10.030)

37 Fan ZX, Hua Q, Li YP, Liu RK \& Yang Z. Interleukin-6, but not soluble adhesion molecules, predicts a subsequent mortality from cardiovascular disease in patients with acute ST-segment elevation myocardial infarction. Cell Biochemistry and Biophysics 201161 443-448. (doi:10. 1007/s12013-011-9209-1)

Received 9 November 2015

Revised version received 15 January 2016

Accepted 19 January 2016 